\title{
How Socratic Pedagogy Works
}

\section{Pete Boghossian}

Portland State University

College of Education

Post Office Box 751

Portland, Oregon 97207

E-mail: pete@boghossian.com

"Wisdom Begins in Wonder" Socrates

What critical thinking is, how it is defined, and whether or not it can be measured are topics that are hotly debated in the philosophical and educational literature. What is not debated, however, is the "urgent need to teach thinking skills at all levels of education" (Carr, 1990). The current literature on Socratic pedagogy frequently addresses why it is important to give reasons for one's positions, and why thinking critically is beneficial for individual students, communities and society. The gap that now needs to be filled is to show the relationship between critical thinking and Socratic pedagogy. To do so it is necessary to first clarify how the Socratic method achieves its epistemological ambitions. Once this is clear, I will go through a step-by-step method explaining how individual educators can implement this in their classrooms. Thus, I will first explain how Socratic pedagogy works and then provide some general guidelines for conducting a Socratic seminar.

\section{Critical Thinking and Socratic Pedagogy}

There is a contentious debate over how to teach critical thinking. However, the two commonly agreed-upon desirable outcomes of critical thinking programs are that they ought to teach students how to engage claims and that they ought to teach them how to do so in a rigorous or systematized way. The Socratic method is a formalized way of teaching students to do both. Professors and teachers can say "Use a critical thinking process!" or "Think critically!" or "Engage the claims!", but even if someone knows what these things mean, that does not entail that they will understand how to do so. By seeing and experiencing the Socratic process, students not only experience an example of what it means to think critically, but they can also come to an understanding of how to employ a mechanism that can be applied in inquiries outside of academia. The elenchus standardizes, and to an extent codifies, this practice. It is a system that clarifies expectations for what constitutes valid justification of a belief, while also giving students an intellectual road map for making clear and coherent arguments and arriving at justified conclusions (Boghossian, 2001).

While Socratic pedagogy has a number of beneficial aspects, it is primarily used to teach students how to think critically through a thoughtful examination of ideas and issues in any discipline (Rudd, 1997). (Socratic pedagogy is not limited to a specific arena of inquiry, like law or philosophy. Teachers can employ Socratic pedagogy in any 
domain of thought, including the "hard sciences," like math, physics, and astronomy.) By substantively engaging claims in a critical way, the Socratic practitioner attempts to help students clarify, justify and clearly articulate their own thoughts. And a substantial corpus of philosophical and educational research literature shows that the Socratic method is, in fact, an extremely effective method of achieving these goals of critical thinking. For example, not only has Socratic pedagogy been found to be "an innovative and powerful instructional device," (Golden, 1984, p. vii) but as a pedagogical approach it shows students how to "think successfully about material in order to be able to understand it, not just passively learn to repeat it under school conditions" (Garlikov, 2001a). But what remains to be explained is how this happens.

\section{Systematic Engagement}

"Thinking successfully" happens through active engagement and a systematic practice. By being asked probing questions about the material, students are forced to engage the subject matter. There is just no way to get around it. It is a substantive engagement of the material, through a fairly simple question-and-answer process, that yields a deeper understanding of the issue being examined (Garlikov, 2001c). But it is not just that students are engaged, but that they are engaged in a systematic way. Systematic engagement rests at the core of Socratic practice.

Let me use an actual classroom example to make this clearer. In one of the ethics classes I teach at a small liberal arts college, my students and I got into a discussion about child pornography. I told them about a new type of child porn, virtual child porn, that dealt only with images of children and not actual children. The argument that has traditionally been made focused on child porn being bad because it hurts children. I claimed that if there are in fact no real children involved then it was no longer clear that child pornography was harmful. My statements particularly shocked one of the students in the class. We had been in class together for several weeks, and he knew that just becoming indignant would get him nowhere. He also believed that my position was so preposterous that it could not possibly be defended. He employed a version of Socratic questioning with me to find out the reasons behind my position.

I told him that not only is it the case that nobody is being harmed, but that it could be that the type of person who would view child porn could actually slake his desires with porn rather than with a child. He asked for evidence but I had none. He then asked for an analogy and I offered the following: Those countries that have legalized prostitution have lower rape rates. Similarly it could be the case that if child porn were legal then there may be fewer incidents of sexual aggression against children; and if this were the case then virtual child porn would actually be a good thing. At this point I think that he was horrified both at the very idea that child porn could have any redeeming value, and that I would even suggest such a thing; but, believing he had the truth and his fellow classmates on his side, he did not relent.

In the absence of empirical data, which neither of us had, he then made the consequentialist claim that this might encourage people who would not ordinarily think about children sexually to start doing so. I then asked him if he was a homosexual. He said no. So I asked him if he views, or desires to view, homosexual pornography. He said 
no again. He anticipated my conclusion by saying, "So you mean to claim that that means that unless someone is predisposed to thinking sexually about children then they won't view child porn?" I nodded, and then asked if frequent viewing of homosexual pornography would make him a homosexual. He said that it would not. By analogy, I told him, we can surmise that someone who is not interested in child porn will not view it, and even if one did view it, for whatever reason, it would not follow that they would then become attracted to children. "So then," I asked, "why would someone who was not sexually interested in children view child pornography?" This was the point that really caused him to pause and examine the justification for his beliefs. Up to this point he had always "just accepted" the fact that child porn was an abomination, but never really thought about why he believed it was intrinsically wrong.

We were employing arguments and making counterexamples, and we were both genuinely engaging an issue that previously he would not even have thought worthy of rising to the level of deserving to be questioned. The conversation ended by him saying that he wanted to look into the issue more on his own, and he decided to weigh the evidence objectively and write his final paper on this subject. He later told me that before his paper he only had belief, but after it he had justified belief, i.e., he was now capable of justifying his position so that it could withstand scrutiny.

Why this example is significant goes to the heart of Socratic practice. The student was genuinely engaged in the subject. He was involved as an active participant in the conversation, presumably to understand the reasons I would have for holding such an ostensibly outrageous belief. But if I am just being naïve and this was not the motivation, then he was engaged for no other reason than that he wanted to prove me wrong and help me to "see the truth of the matter." Because he had been steeped in the method, his use of questioning techniques was spontaneous and even natural. It was neither the case that he had to deliberate over how to proceed, nor even give up attempting to engage critically the issue and turn the discussion to my personal moral shortcomings by resorting to ad hominem attacks. He knew how to effectively ask questions and refute examples so as to expose fallacies and inconsistencies in my argumenteven if the conclusion did not warrant univocal assent. We both went through a process of engaging an idea, and what was important was more that process and less the conclusion. In this case the student came into the dialogue with a strong moral intuition, and came out with a justified belief.

Of course this does not discount the fact that he could have been engaged only because it was a controversial issue, and controversial issues may garner more interest than pedestrian ones. But he manifested his engagement in a systematic way by asking me focused and directed questions that forced me to support my assertions. This shows that he had to be thinking about the material, and this is exactly what it means to be engaged. So, not only did he engage an assumption, but he also now had the tools to do so in a fair and thoughtful manner. In this example we were both employing a modified version of the elenchus: Asking why, using counterexamples, and probing each other's positions for internally consistency.

Significantly, and what is often overlooked in the literature on the Socratic method, is that the other students were watching this method of inquiry (Schmid, 1998). It was 
being publicly modeled for them. In a Socratic environment, the focus is not just on the student and the teacher (in fact, the best Socratic learning environments occur when there are diverse views added to the discourse) but on a way to think about issues and critically engage claims. Socratic pedagogy impacts the entire learning community because even those students who are hesitant to speak up in class can benefit from seeing a genuine discourse modeled. Students were not learning about what it means to think critically by reading about how to construct syllogisms, or being told the essential elements of cogent reasoning, or learning how to write arguments in symbolic logic, or learning how to tag a fallacy with a Latin name. Students were witnessing a discourse that involved real people discussing a real issue that has consequences beyond the classroom. They were also having a systematic process, which they themselves can employ, modeled for them.

So the Socratic method helps all students, particularly those who are apathetic and disaffected, engage the material in a way that has meaning for them. Learning to become a critical thinker is not just the province of the smarter, more active, more vocal students. The Socratic process makes the tools of inquiry available to all participants. In The Socratic Method: Teaching by Asking Instead of by Telling, Garlikov correctly notes that, "students do not get bored or lose concentration if they are actively participating" (Garlikov, 200lb). While this may seem to be an obvious goal of any pedagogy - to help students engage the material rather than be passive "banking" receptacles (Freire, 1970)use of Socratic teaching techniques have been shown to be an especially effective "way to interact with students that [sic] are not particularly interested in the subject matter" (Klein, 1998).

Hopefully, by examining a contemporary example of Socratic practice, how Socratic pedagogy works and how it fosters critical thinking have become clear. Socratic pedagogy encourages active engagement of an idea and provides students with a process that can be used to analyze and clarify claims. It is this systematized process or critical way of thinking about claims that is at the core of Socratic practice. Ideally, Socratic practice is not just a process used by teachers to engage students, but a way of thinking that we impose upon ourselves.

\section{General Guidelines, Do's and Don't's}

Hopefully, it is now clear how the Socratic method works. The next step, then, is to explore how to use that understanding. The following is a step-by-step guide to implementing the Socratic method. Within this guide there are some specific dos and don'ts for each stage of the Socratic method.

1. Start by examining a claim or asking a question. Claims can be about anything, e.g., "Tuition is too high here," or "The war in Afghanistan is unjust," or, my personal favorite, "This is stupid, why should we be forced to learn this?" In the example used in the paper, my students were talking about the evils of child pornography. They made the claim that child pornography was morally wrong, and this started the hour-long Socratic session that followed.

Do make it clear, before the dialogue begins, that there is a difference between the person and the proposition. What is at issue are the claims people 
make, and their reasoning, and not the people who make the claims (i.e., not those who reason) (Boghossian, 2002).

Do encourage all students to participate. The more voices that are added to the discourse the richer the dialogue!

2. Understand first. Sometimes the claim will be fairly straightforward. Unfortunately, however, not all claims are clear, and students frequently do not say what they mean. Therefore, it is important to ask students exactly what they mean and allow them to clarify and explain their statements. (This also teaches students to be linguistically precise). If something that is said is not clear, then ask clarifying questions.

In the example used in this paper, questions arise such as, "What exactly do you mean by 'pornography'? Whose standards of moral wrongness are you invoking? Is actual child pornography morally different from virtual child pornography? How is 'child' defined? To what extent is the notion of child transferable to the virtual realm?" These are examples of questions that I could have developed early on, but unfortunately did not. Because I was engaged in a conversation that I found to be very interesting, I jumped ahead without being as careful and methodical as I ought to have. An ironic shortcoming of Socratic practice is that because the process of critically engaging ideas is inherently interesting, it may lead one to forget about methodological rigor.

Don't be afraid to say, "I don't know." Socratic discourses start in wonder. If you do not know something then that is okay, you are wondering about it, and that is one of the reasons that you are inquiring.

3. Offer a counterexample. The most famous counterexample can be found in the beginning of Plato's Republic regarding the definition of justice. When Socrates asks what justice is, one of the responses he receives is that justice is "paying one's debts." Socrates then offers the following counterexample, "What if you borrow a knife from a man who later becomes homicidal and demands the knife back? Is it just to give it back to him?" The idea here is that of course it is not just, therefore there must be something wrong with the original definition of justice.

Counterexamples serve to call the original proposition into question. Similarly, a counterexample used in this paper is:

Claim:

Child porn will cause people who don't think about children sexually to start doing so.

Counterexample:

Homosexual pornography will cause men who don't think about men sexually to start doing so. Lesbian pornography will cause women who don't think about women sexually to start doing so.

Counterexamples can be used in response to a claim. The use of this counterexample does not serve to undermine the initial claim (that child porn is morally wrong), but one of the subsequent claims (that viewing child pornography will cause people to start 
thinking sexually about children). This subsequent claim is intended to support the initial claim that child pornography is morally wrong. Ideally, as an instructor, you would make the process explicit and explain what role the counter example plays. For example:

"You have given a reason to support your central conclusion that child pornography is morally wrong. The problem with that argument, however, is that the premise is false. This can be shown by means of a counterexample. You said, 'Child porn leads people who don't think about children sexually to start doing so.' Here is the counterexample against the truth of the claim: 'Homosexual porn does not cause males who don't think about men sexually to start doing so."

Depending on the level of your students, one could capitalize on the situation and quickly get into the logic of the counterexample by showing why it is effective. For example:

"The premise you have offered assumes that the mere exposure, even if repeated often, will be sufficient to cause someone to have a certain sexual attitude. The counterexample I offered satisfies that condition, but there is no resulting sexual attitude. Therefore, that exposure, even if repeated often, is not a sufficient condition for that sexual attitude. Moreover, not only is the premise offered here false, but even if it were true it would not be sufficient to warrant belief in the conclusion that child pornography is morally wrong. Here is a counterexample against the inference (as opposed to a counterexample against the truth of a claim):

It is possible that:

- Child porn will cause people who don't think about children sexually to start doing so. (Here I will accept the truth of your premise by fiat.) AND

- What if those people who enjoy child pornography neither act upon it, nor act immorally toward children. AND

- It is not the case that child porn is morally wrong. (Here the intended conclusion is negated, assumed false, in order to show that the fact that the premise is true does not guarantee, is not sufficient for, the truth of the conclusion.)

This counterexample (by possible conjunction) shows that it is possible for the premise to be true and the conclusion false. Therefore, it shows that the premise you offered is not sufficient for the conclusion-it does not guarantee the conclusion."

The effectiveness of this counterexample (by possible conjunction) depends on the moral standards adopted at the beginning of the discussion. If those standards have not been discussed earlier, then such a counterexample becomes an opportunity to address them.

Do make examples accessible. Remember your audience. Use examples and counterexamples that your students can relate to. If students cannot relate to an example then it will not be effective. 
Don't lose track of your subject. Integrate Socratic pedagogy with the particular subject matter that you are teaching. Use it as a tool to enable students to think critically about the subject.

Do delight in being shown by students that your arguments are in error! In Plato's Gorgias Socrates asks his interlocutors if they are like him - he likes to refute and be refuted, but prefers the latter. It is truly the ultimate compliment if your students use the Socratic method to point out errors in reasoning that you make.

4. Repeat and relate to the initial claim. Continue to examine subsequent claims and offer counterexamples. Make sure that students understand the argumentative function of the additional claims, and that they understand how the claims relate to each other. If you feel comfortable with argument mapping, then it may be useful to map out the reasoning by diagramming it on the board so that the class will be able to see how the arguments is developing.

Ideally students will anticipate your questions and offer counterexamples of their own. For example, when I asked a student if he was a homosexual he had already anticipated where I was going with the question. He knew that I would use the response to show that people who were already predisposed to finding children sexually attractive would be the ones who would view child pornography. If my counterexample is true (child pornography would not cause people to think of children sexually who did not already think of them sexually) then what does this mean for the initial claim that child pornography was immoral? Is it undermined? Is child pornography still immoral if only pedophiles view it? Continue to relate the discussion to the initial claim. Be explicit and ask your students how, if at all, the initial claim is impacted by the discussion.

Don't accept conclusions that do not follow from the premises. This may seem obvious, but it is our natural inclination to be more forgiving of one's reasoning if it leads to conclusions that accord with our intuitions.

5. It ends when it ends. And if a Socratic seminar does not end, then that's okay too. Let the dialogue flow without feeling the need to artificially cut it off (because, for example, students are getting too involved, or because you "need" to cover additional material, or because of the feeling that there needs to be some resolution, or even because you fear offending them by opening an avenue for them to critically examine their beliefs). You are doing exactly what you need to be doing, and so are your students. You are teaching them a way of thinking and helping them to develop a process for engaging ideas.

It may be valuable to end the discussion 10 minutes before the class ends, and give everyone, including yourself, time to summarize and reflect on the discourse. This can be done in writing, or, depending on your pedagogical style, verbally. You can randomly call upon students to read or go over the main points of their summaries, and/or to collect them if appropriate. This would give you the opportunity to monitor students' learning, and to model the skill of summarizing. (If you choose to have your students 
summarize the discussion in writing, I highly suggest that you do the same, and share that with students when it is appropriate.) Summarizing has the additional benefit of making students aware of what they have learned, reinforcing and concretizing their learning, and giving them a sense of completion even if there is no final resolution of the discussion. Consequently, this diminishes some of the frustration that typically results in the absence of a final resolution.

Do know when to stop. Gauge student responses and see if it is appropriate to continue. Occasionally students may become quite upset if they feel their fundamental beliefs are being challenged-especially if they have no response to your queries. Every situation is different, so use your best judgment.

Don't force it. If a Socratic session happens then it happens. Do not force students to come up with claims so that you can generate counterexamples, and do not ask questions just to ask questions. This is an artificial way of making a dialogue and it will feel contrived.

Don't get discouraged. When first starting it is difficult to develop counterexamples quickly, think on your feet for long periods of time, remember all of the different claims and counterexamples, etc. Remember the ancient Japanese proverb, "We learn by doing, there is no other way."

\section{Conclusion}

Socratic pedagogy is an extremely effective way to help students think critically. It teaches students - even when outside of an academic environment-how to systematically engage ideas. Systematic engagement is a vital component of a larger truth-seeking enterprise that is often overlooked in contemporary educational practice. By incorporating Socratic elements in the classroom, your contribution will extend beyond just teaching students a way to think. It ultimately help to engender a love of the truth.

\section{References}

(Author Unknown, 1998). Critical Thinking Skills and Teacher Education. ERIC Digest 388, ERIC Clearinghouse on Teacher Education, Washington, DC. http://ericae.net/ edo/ed297003.htm

Boghossian, P. (2001). "How to Make an Argument." Center for Excellence in Learning and Teaching (CELT) sponsored conference, Critical Reasoning and Problem Solving: Inquiry, Discovery and Problem Solving in Undergraduate Education, at SUNY Stony Brook, June 22, 2001. 
Boghossian, P. (2002). "Socratic Pedagogy, Race, and Power: From People to Propositions." Education Policy Analysis Archives. http://epaa.asu.edu/epaa/

Carr, K. (1990). How Can We Teach Critical Thinking? Clearinghouse on Elementary and Early Childhood Education. University of Illinois at Urbana-Champaign Children's Research Center. ERIC Digest. http://ericps.crc.uiuc.edu/eece/pubs/digests/1990/ carr90.html

Freire, P. (1970). Pedagogy of the Oppressed. The Continuum International Publishing Group: New York, New York.

Klein, H. (1998). Creative Teaching. World Association for Case Method Research and Application, Act 1, Lucerne, Switzerland. http://www.rh.edu/ chan7578/wacra/ abstract_act1.html

Garlikov, R. (2001a). Understanding, Shallow Thinking, and School. http:// www.garlikov.com/teaching/Understanding.html

Garlikov, R. (2001b) The Socratic Method: Teaching by Asking Instead of by Telling. http://www.garlikov.com/Soc_Meth.html.

Garlikov, R. (2001c). Having Understanding Versus Knowing Correct Explanations. http://www.garlikov.com/Interpretation.html

Golden, J. (1984). "Plato Revisited: A Theory of Discourse for All Seasons." Essays on Classical Rhetoric and Modern Discourse. Ed. Connors, R., Ede, L., Lunsford, A. Carbondale, IL: Southern Illinois UP. As found in, Whipple, R. (1997). Socratic Method and Writing Instruction. University Press of America: Lanham, MD.

Rud, A. (1997). Education Policy Analysis Archives. The Use and Abuse of Socrates in Present Day Teaching. Volume 5, Number 20. http://epaa.asu.edu/epaa/v5n20.html.

Schmid, W. (1998). Socratic Paideia: How It Works and Why 1t So Often Fails. Twentieth World Congress of Philosophy, Boston, MA.

Strong, M. (1997). The Habit of Thought: From Socratic Seminars to Socratic Practice. Chapel Hill, North Carolina: New View.

Walsh, D., \& Paul, R. (1988). The Goal of Critical Thinking: From Educational Ideal to Educational Reality. Washington, D.C.: American Federation of Teachers. 